\title{
Volume and Cost of Cylindrical Shaped Silo with Conical Roof
}

Gabriel Mitzakoff Parola

University of South Florida

\author{
Advisors: \\ Arcadii Grinshpan, Mathematics and Statistics \\ Scott Campbell, Chemical and Biomedical Engineering \\ Marcio Salvadego, Moinho Paulista, Brazil \\ Problem Suggested By: Marcio Salvadego
}

Follow this and additional works at: https://digitalcommons.usf.edu/ujmm

Part of the Mathematics Commons

UJMM is an open access journal, free to authors and readers, and relies on your support:

Donate Now

\section{Recommended Citation}

Mitzakoff Parola, Gabriel (2021) "Volume and Cost of Cylindrical Shaped Silo with Conical Roof,"

Undergraduate Journal of Mathematical Modeling: One + Two: Vol. 12: Iss. 1, Article 5.

DOI: https://doi.org/10.5038/2326-3652.12.1.4938

Available at: https://digitalcommons.usf.edu/ujmm/vol12/iss1/5 


\title{
Volume and Cost of Cylindrical Shaped Silo with Conical Roof
}

\begin{abstract}
This project utilizes integral calculus to find the exact volume of a non-uniform cylindrical-shaped silo used to store wheat and calculate the cost of material utilized to build such silo. Due to its non-uniform shape, the silo is divided into two sections and the volume of each is calculated. The final volume for the silo with the measurements provided is approximately 2330.02 meters cubic and surface area of 1074.96 meters squared, which is considered to be a large capacity silo. With such a large capacity silo there are costs to be considered, such as the material cost which is calculated for steel.
\end{abstract}

\section{Keywords}

silo, volume, surface area, conical roof, material cost

\section{Creative Commons License}

(c) (i) (2)

This work is licensed under a Creative Commons Attribution-Noncommercial-Share Alike 3.0 United States License. 


\section{PROBLEM STATEMENT}

Calculate the volume of a cylindrical-shaped silo with a conical roof with a diameter of 10

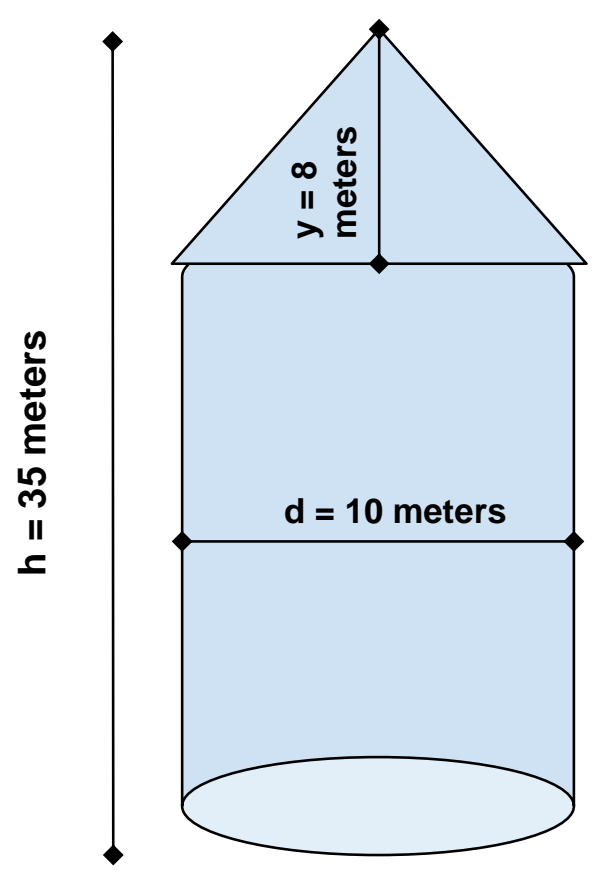

meters, 35 meters in height, and calculate the cost for the material utilized for such silo considering its surface area and thickness of 0.01 meters. 


\section{MOTIVATION}

The use of silos is extremely frequent in a variety of industry segments, but mostly present in the agricultural sector. Efficiently capable of storing large quantities of grains its use is almost necessary for any large-scale agricultural producer such as the company Moinho Paulista $^{1}$. According to the specific demand for storage, silos are built with a specified volume and with a designated material depending on what grain will be stored. This process of calculating the volume and the material cost for the silo can be done through integral calculus.

\section{MATHEMATICAL DESCRIPTION AND SOLUTION APPROACH}

Because of its irregular shape, the silo is divided into two sub-sections in order to calculate the volume for each section. Figure 1 can be dissected into a regular cylinder, shape "alpha" and into a cone, shape "beta". The volume for "alpha" can be obtained utilizing the known formula (1) for the volume of a cylinder while the volume for "beta" requires the use of integral calculus. $^{2}$

$$
\begin{aligned}
& \text { Volume }_{\text {total }}=\text { Volume }_{\alpha}+\text { Volume }_{\beta 3} \\
& \text { Volume }_{\alpha}=\pi \times r^{2} \times \text { height }
\end{aligned}
$$

Volume $_{\alpha}=\pi \times\left[\frac{10}{2}\right]^{2} \times(35-8)$

\footnotetext{
1 "O Moinho Paulista Muda Marca de Sua Comunicação Institucional | Nita Alimentos."

2 Stewart, Essential Calculus.

3 "Online LaTeX Equation Editor - Create, Integrate and Download."
} 


\section{Volume $_{\alpha} \approx 2120.58$ meters $^{3}$}

The volume for cone "beta" is not calculated using a standard formula. To find it through integration the cone is divided into infinitesimally small slices defined as "dz" and the radius for each slice is defined as the distance " $y$ ", see Figure 1. Therefore, the volume for the cone is the sum of the volumes for all these slices, which is defined by the following integral:

$$
\begin{aligned}
& \text { Volume }_{\text {slice }}=d z \times \pi \times y^{2} \\
& \text { Volume }_{\beta}=\int_{a}^{b} \pi \times y^{2} d z
\end{aligned}
$$




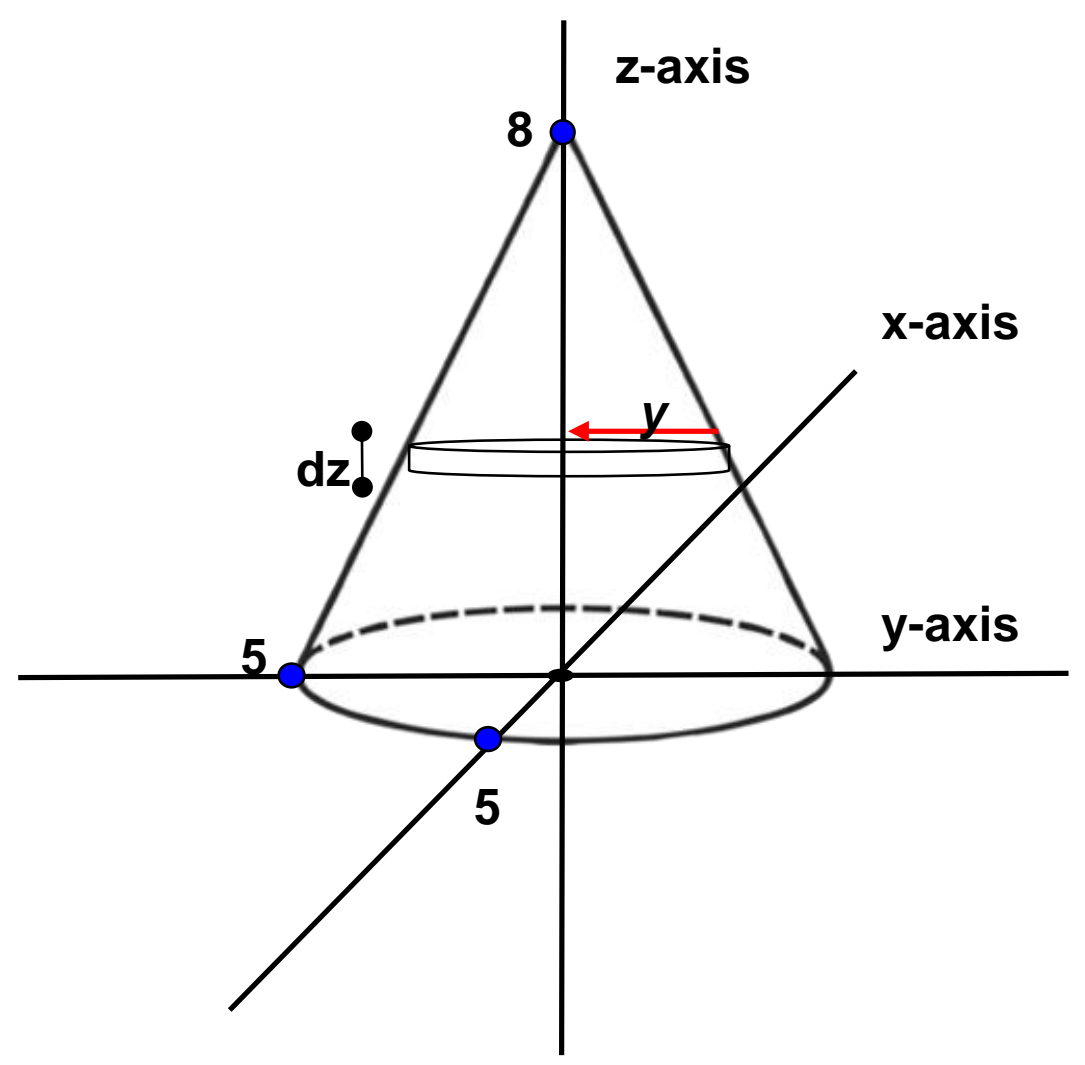

Figure 1 - silo's conical section

However, the function $y$ is not defined yet. To derive the integral and calculate the volume, a function $y$ must be defined. The integral formula derived for the value of "beta" is applicable to any function, defined and approximated accordingly to the problem. For this specific scenario, in order to find the formula for $y$, it is assumed that the cone sides are approximately defined by a linear function. Thus, the function $y(z)$ can be defined by plugging the values specified for the silo in the following linear equation:

$$
\begin{aligned}
& z=m y+b \\
& y=\left(5-\frac{5 z}{8}\right)
\end{aligned}
$$


Once the equation (2) for $y$ is obtained, its value is used in the integral developed for the volume of the cone:

Volume $_{\beta}=\int_{a}^{b} \pi \times\left(5-\frac{5 z}{8}\right)^{2} d z$

Now that the integral for the cone has been found the boundaries for integration must be defined. Considering the silo measurements provided, the final integral (3) for the volume of "beta" is derived:

Volume $_{\beta}=\int_{0}^{8} \pi \times\left(5-\frac{5 z}{8}\right)^{2} d z$

Volume $_{\beta}=25 \pi(8-8+8 / 3) \approx 209.44$ meters $^{3}$

Once each section is calculated, the total volume for the silo is simply the sum of each individual section's volume:

$$
\text { Volume }_{\text {total }} \approx 2120.58+209.44 \approx 2330.02 \text { meters }^{3}
$$

Thus the total volume of the silo is approximately 2330.02 meters cubic. The cost of materials utilized to build such a silo must also be calculated based on the thickness of the walls. In order to do that the surface area for the silo must be calculated for the two different sections, "alpha" and "beta". The surface area for "alpha" is defined by the known formula (4):

Surface $A_{\alpha}=(2 \pi \times r \times$ height $)+\left(\pi r^{2}\right)$ 
Surface $A_{\alpha} \approx 926.77$ meters $^{2}$

For the surface area of "beta", the use of calculus is present again ${ }^{4}$. First, the formula for the surface area of a revolution is given as the following:

$\operatorname{Surface} A_{\beta}=\int_{a}^{b} 2 \pi \times(y) \times\left(\sqrt{1+\left(y^{\prime}\right)^{2}}\right) d z$

As $y(z)$ is approximated by a linear function (2) its derivative is approximated by a constant, $y^{\prime}(z)=-5 / 8$, and the final integral (5) for the surface area of "beta" is evaluated with the values defined for the silo:

Surface $A_{\beta}=\int_{0}^{8} 2 \pi \times\left(5-\frac{5 z}{8}\right) \times\left(\sqrt{1+\left(\frac{-5}{8}\right)^{2}}\right) d z$

Surface $_{\beta} \approx 5 \pi \times \sqrt{89} \approx 148.19$ meters $^{2}$

Once each section is calculated, the total surface area for the silo is simply the sum of each individual section's area:

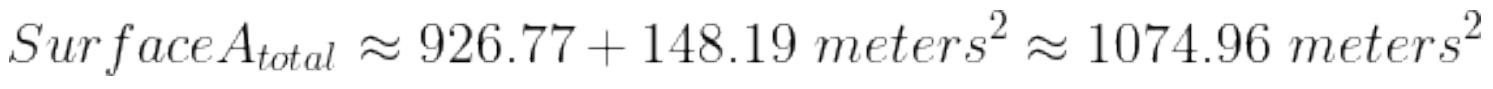

${ }^{4}$ Stewart, Essential Calculus. 
Based on the total surface area calculated and the thickness provided for the silo, a table for the cost per kilogram of steel is constructed. To calculate the total amount of steel used in this silo, an approximation considering equivalent of one cubic meter of steel to 7800 kilograms of steel is utilized ${ }^{5}$.

Table 1.1 - Material cost per kg

\begin{tabular}{|l|l|}
\hline Material & Steel \\
\hline Lower boundary price & $0.93 \$$ \\
\hline Upper boundary price & $1.66 \$$ \\
\hline
\end{tabular}

Table 1.2 - Total estimated cost for silo (see Appendix)

\begin{tabular}{|l|l|}
\hline Material & Steel \\
\hline Lower boundary price & $77,907.96 \$$ \\
\hline Upper boundary price & $139,061.52 \$$ \\
\hline
\end{tabular}

\section{DISCUSSION}

The project successfully calculates the theoretical volume, surface area and gives an estimated cost of materials for the construction of a spherical silo with a conical roof. The silo is specified to have a diameter of 10 meters and a total height of 35 meters. The values calculated for such

5 "Weight of Common Engineering Metals, in Kilograms per Cubic Metre." 
silo demonstrates its large capacity of storage of roughly 2330 cubic meters of volume. With such a large capacity, the costs for materials are also relatively high. Calculations for the price are made based on the price per kilogram for steel, which is the material analyzed to build the silo in this scenario. Steel is the material chosen based on the suggestion of the president of Moinho Paulista, a company in Brazil that works in the agricultural sector, mostly dealing with grains. The president's suggestion is based on a future project for the company in which they are planning to build a silo mainly consistent with steel.

A recent explosion in the company due to inadequate storage of the grains led to an increase in safety measures. The airborne grain dust is explosive if in contact with any source of ignition. Steel is considered to provide a great container that is able to have great grain aeration while also not enabling any dust to form that could lead to an explosion ${ }^{6}$. Aside from that, steel silos are considered to be relatively fast to be built compared to other materials such as concrete or wood ${ }^{7}$.

\section{CONCLUSION AND RECOMMENDATIONS}

The volume for the silo specified with a diameter of 10 meters, the height of 35 meters, and thickness of 0.01 meters was calculated utilizing integral calculus. Once the volume was calculated, the surface area for the silo was also calculated through the use of integral calculus. Based on the surface area of the silo and utilizing the thickness determined at 0.01 meters, the calculations for total costs of materials to build such silo were performed, considering a silo made up of steel. The price was calculated utilizing the price per kilogram of steel. After all the calculations are performed, it can be concluded that the silo in the proposed problem is a large capacity silo and also has a relatively high cost regarding the amount of steel necessary to build it.

Based on the information provided by the president of the company and considering the past events he described, it seems that an investment to build a silo with the specified measurements

\footnotetext{
6 “1990ME_PauloEstevesJunior.Pdf."
}

7 "4274428.Pdf." 
from the problem is an interesting investment. The silo would not only be a safer storage option regarding dust formation but steel silos are also efficient with grain aeration, directly impacting the quality of the product produced by the company. It must be considered, however, that such a large silo will only return its initial investment after a longer period of time due to its relatively high initial investment. Thus, before any action is taken regarding the construction of a new silo, a net present value for the investment must be made and compared to any other possible investments the company is currently considering.

Another recommendation regarding this project would be to analyze the cost for other materials, not only steel which would enable a more thorough comparison between materials and costs. The opportunity cost for each material could be analyzed in detail as well.

\section{NOMENCLATURE}

\begin{tabular}{|ll|l|}
\hline$r$ & & Radius \\
\hline & $\alpha$ & Cylindrical section \\
\hline & $\beta$ & Conical section of silo \\
\hline$z$ & & Height for the conical section \\
\hline$d z$ & & Height for conical section slices \\
\hline$y$ & & Linear function based on $\mathrm{z}$ \\
\hline
\end{tabular}




\section{REFERENCES}

"1990ME_PauloEstevesJunior.Pdf."

http://web.set.eesc.usp.br/static/media/producao/1990ME_PauloEstevesJunior.pdf.

“4274428.Pdf.” Accessed May 6, 2021. https://core.ac.uk/download/pdf/4274428.pdf.

“O Moinho Paulista Muda Marca de Sua Comunicação Institucional | Nita Alimentos.” 2021. http://www.nitaalimentos.com.br/novidades/o-moinho-paulista-muda-marca-de-suacomunicacao-institucional/.

"Online LaTeX Equation Editor - Create, Integrate and Download." https://www.codecogs.com/latex/eqneditor.php.

Stewart, James. Essential Calculus. 2nd ed. Belmont, CA: [Mason, Ohio?]: Brooks/Cole ; Cengage Learning [distributor], 2013.

"Weight of Common Engineering Metals, in Kilograms per Cubic Metre." Accessed May 6, 2021. https://kvsteel.co.uk/steel/weights2.html. 


\section{APPENDIX}

Volume for a cylinder: $V=\pi \times r^{2} \times$ height

The total surface area for a cylinder: $S A=2 \pi \times r \times$ height $+\left(2 \pi \times r^{2}\right)$

Integral surface area of a revolution: $S A=\int_{a}^{b} 2 \pi \times f(x) \times\left(\sqrt{1+\left(f^{\prime}(x)^{2}\right)}\right) d x$

Integral for the volume of a cone: $V=\int_{a}^{b} \pi \times f(x)^{2} d x$

Conversion from squared meters to cubic meters:

1074.96 meter $^{2} \times 0.01$ meters $\approx 10.74$ meter $^{3}$

Conversion from cubic meters to kilograms of steel:

10.74 meters $^{3} \times \frac{7800 \text { kilograms }^{2}}{1 \text { meter }^{3}}=83772$ kilograms of steel

Cost calculation based on price per kilogram:

$83772 \times 0.93 \approx 77907.96$ dollars - lower boundary

$83772 \times 1.66 \approx 139061.52$ dollars - upper boundary 